\title{
PERANCANGAN IDENTITAS VISUAL UNIVERSITAS ISLAM KALIMANTAN MUHAMMAD ARSYAD AL BANJARI
}

\author{
Tri Wahyu Qur'ana \\ Fakultas Teknologi Informasi, Universitas Islam Kalimantan Muhammad Arsyad Al-Banjari \\ twqurana@gmail.com \\ Abdurrahman Sidik \\ Fakultas Teknologi Informasi, Universitas Islam Kalimantan Muhammad Arsyad Al-Banjari \\ abdurrahmansidik30@gmail.com
}

\begin{abstract}
ABSTRAK
Penggunaan lambang dan logo saat ini masih banyak yang tidak sesuai dengan fungsi dan tujuannya dibuat. Apabila mengacu pada pengertiannya, lambang dan logo memiliki makna yang berbeda pula. Penggunaan lambang dan logo juga banyak digunakan pada perguruan tinggi di Indonesia. Beberapa perguruan tinggi yang menggunakan lambang dan logo yaitu Universitas Indonesia, Universitas Negeri Malang, Universitas Brawijaya, Universitas Muhammadiyah Malang, Institut Teknologi Sepuluh Nopember, dan lainnya. Lambang digunakan untuk kepentingan internal di dalam perguruan tinggi, seperti penggunaan dalam spanduk acara di dalam kampus, skripsi, penulisan tugas dan makalah atau karya ilmiah. Sedangkan logo digunakan untuk kepentingan eksternal yang hubungannya dengan stakeholder perguruan tinggi, seperti kepentingan dengan instansi mitra dan atau alumni. Universitas Islam Kalimantan Muhammad Arsyad Al Banjari hingga saat ini hanya menggunakan lambang dan tidak mempunyai logo. Lambang dan logo mempunyai peran dalam membentuk identitas visual perguruan tinggi. Identitas visual erat kaitannya dengan brand. Tujuan utama dalam membangun identitas visual yaitu agar produk atau jasa yang ditawarkan mampu melekat dengan kuat dalam pikiran dan hati konsumen. Jika dikaitkan dengan penelitian ini yaitu identitas visual perguruan tinggi seperti lambang dan logo berfungsi sebagai pembeda perguruan tinggi dengan yang lainnya, penerapan visi dan misi, kumpulan berbagai atribut fisik, emosi, pemahaman logis, karakteristik, performa, aset, dan janji dari perguruan tinggi itu sendiri. Peneliti melakukan perancangan identitas visual berupa logo Universitas Islam Kalimantan Muhammad Arsyad Al Banjari untuk memperkuat brand yang telah dibangun agar dapat dikenal masyarakat secara luas.
\end{abstract}

Kata Kunci: Brand, Desain, Identitas Visual, Logo

\section{PENDAHULUAN}

Penggunaan lambang dan logo saat ini masih banyak yang tidak sesuai dengan fungsi dan tujuannya dibuat. Jika mengacu pada Kamus Besar Bahasa Indonesia, lambang adalah sesuatu seperti tanda (lukisan, lencana, dan sebagainya) yang menyatakan suatu hal atau mengandung maksud tertentu. Lambang juga berarti tanda pengenal yang tetap (menyatakan sifat, keadaan, dan sebagainya). Sedangkan logo adalah huruf atau lambang yang mengandung makna, terdiri atas satu kata atau lebih sebagai lambang atau nama perusahaan dan sebagainya.

Apabila dilihat dari sejarahnya lambang menurut Rustan [1] digunakan sebagai bentuk identifikasi kepemilikan. Contoh penggunaan lambang seperti pemberian cap untuk menandai hewan ternak menggunakan besi panas. Hal ini berfungsi untuk memudahkan penyembelih untuk mengidentifikasi dari peternakan mana hewan tersebut berasal. Seiring dengan berkembangnya zaman, lambang memiliki

fungsi yang lebih luas seperti untuk melindungi hasil cetak dari pembajakan atau sebagai jaminan kualitas tinggi sebuah produk. Hingga pada tahun 1875 sebuah perusahaan minuman Bass \& Co. Brewery membuat sebuah lambang agar membedakan perusahaannya dengan perusahaan lainnya. Lambang Bass \& Co. Brewery diakui sebagai merek dagang (trademark) pertama di dunia. 
Sedangkan istilah logo menurut Harper dalam Rustan [1] baru muncul pada tahun 1937 yang merupakan kependekan dari logotype. Logotype diartikan sebagai tulisan nama entitas didesain secara khusus dengan menggunakan teknik, jenis huruf, dan gambar tertentu. Dari istilah yang dijelaskan dapat disimpulkan bahwa fungsi dan tujuan yang berbeda dalam penggunaan lambang dan logo.

Penggunaan lambang dan logo juga banyak digunakan pada perguruan tinggi di Indonesia. Beberapa perguruan tinggi yang menggunakan lambang dan logo yaitu Universitas Indonesia, Universitas Negeri Malang, Universitas Brawijaya, Universitas Muhammadiyah Malang, Institut Teknologi Sepuluh Nopember, dan lainnya.
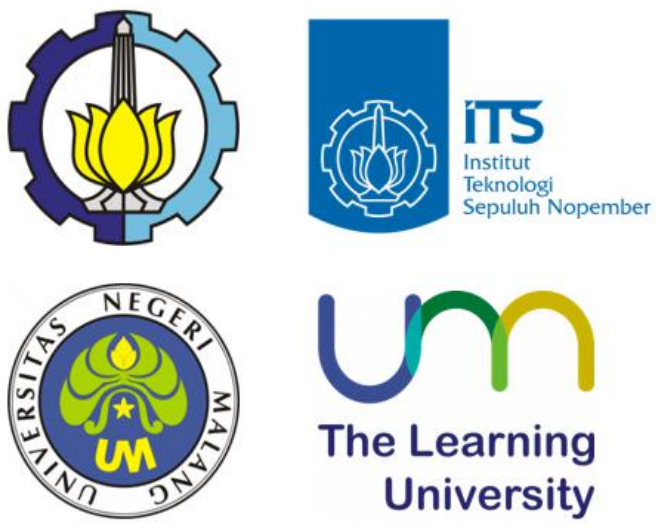

Gambar 1 Penggunaan lambang (kiri) dan logo (kanan) pada Institut Teknologi Sepuluh Nopember dan Universitas Negeri Malang.

Lambang digunakan untuk kepentingan internal di dalam perguruan tinggi, seperti penggunaan dalam spanduk acara di dalam kampus, skripsi, penulisan tugas dan makalah atau karya ilmiah. Sedangkan logo digunakan untuk kepentingan eksternal yang hubungannya dengan stakeholder perguruan tinggi, seperti kepentingan dengan instansi mitra dan atau alumni.

Universitas Islam Kalimantan Muhammad Arsyad Al Banjari hingga saat ini hanya menggunakan lambang dan tidak mempunyai logo. Lambang dan logo mempunyai peran dalam membentuk identitas visual perguruan tinggi. Identitas visual erat kaitannya dengan brand. Brand sendiri menurut Lamb, Hair, dan McDaniel [2] adalah nama, istilah, simbol, desain, atau gabungan keempatnya, yang mengidentifikasi produk penjual dan membedakannya dari produk pesaing. Tujuan utama dalam membangun identitas visual yaitu agar produk atau jasa yang ditawarkan mampu melekat dengan kuat dalam pikiran dan hati konsumen. Jika dikaitkan dengan penelitian ini yaitu identitas visual perguruan tinggi seperti lambang dan logo berfungsi sebagai pembeda perguruan tinggi dengan yang lainnya, penerapan visi dan misi, kumpulan berbagai atribut fisik, emosi, pemahaman logis, karakteristik, performa, aset, dan janji dari perguruan tinggi itu sendiri. Peneliti melakukan perancangan identitas visual berupa logo Universitas Islam Kalimantan Muhammad Arsyad Al Banjari untuk memperkuat brand yang telah dibangun agar dapat dikenal masyarakat secara luas.

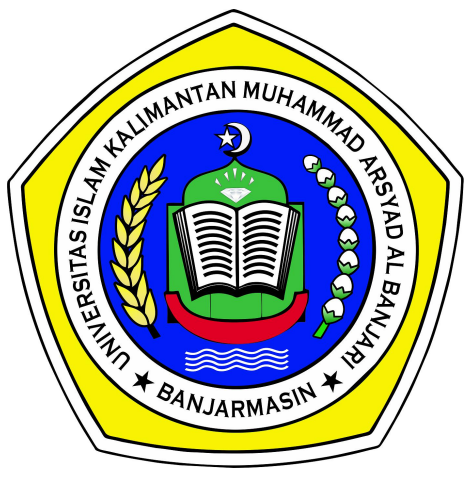

Gambar 2 Logo Universitas Islam Kalimantan Muhammad Arsyad Al Banjari

\section{METODE PENELITIAN}

Penelitian ini menggunakan metode Research \& Development (R\&D) yaitu menurut Sugiyono [3] adalah metode yang digunakan untuk meneliti dalam upaya menciptakan produk yang telah ada (inovasi) maupun menciptakan produk baru (kreasi). Peneliti mengumpulkan informasi secara lengkap dengan menggunakan berbagai prosedur pengumpulan data berdasarkan waktu yang telah ditentukan, kemudian menyimpulkan dan membuat rancangan identitas visual Universitas Islam Kalimantan Muhammad Arsyad Al Banjari. 
Peneliti menggunakan dua instrumen untuk mendapatkan hasil yang lebih akurat, yaitu dokumentasi dan wawancara. Peneliti mengumpulkan dokumen-dokumen kualitatif seperti buku, jurnal, surat kabar, maupun artikel-artikel, foto, dan video yang didapatkan secara pribadi dan di internet dari situs-situs kredibel dan terpercaya. Dokumen-dokumen tersebut akan dikaitkan satu sama lain untuk mendapatkan hasil penelitian yang lebih akurat.

Selama proses penelitian, peneliti mencoba untuk tidak bertumpu pada satu instrumen penelitian saja agar data yang dihasilkan lebih objektif. Wawancara digunakan sebagai teknik pengumpulan data untuk menemukan permasalahan yang diteliti, dan juga untuk mengetahui hal-hal dari partisipan yang lebih mendalam. Peneliti akan melakukan face-to-face interview (wawancara berhadap-hadapan) atau telepon dengan partisipan. Peneliti akan memberikan pertanyaan-pertanyaan umum tidak terstruktur hingga pertanyaan-pertanyaan bersifat terbuka yang dirancang untuk memunculkan pandangan dan opini dari para partisipan.

Setiap perguruan tinggi membutuhkan sebuah identitas, yang mana identitas tersebut dapat diwakilkan dalam bentuk visual seperti teks, gambar, atau gabungan keduanya. Bentuk visual yang digunakan harus merepresentasikan entitas yang diwakili. Identitas visual ini salah satunya adalah lambang dan logo. Pada bab pendahuluan telah dijelaskan bahwa terdapat perbedaan dari segi fungsi dan tujuan lambang dan logo. Lambang digunakan untuk kepentingan internal di dalam perguruan tinggi, seperti penggunaan dalam spanduk acara di dalam kampus, skripsi, penulisan tugas dan makalah atau karya ilmiah. Sedangkan logo digunakan untuk kepentingan eksternal yang hubungannya dengan stakeholder perguruan tinggi, seperti kepentingan dengan instansi mitra dan atau alumni.

Logo merupakan sebuah identitas visual yang digunakan untuk menggambarkan citra atau karakter dari suatu lembaga atau perusahaan atau organisasi. Berbeda dengan lambang, logo mempunyai bentuk dan warna yang lebih dinamis. Sebuah logo diperoleh maknanya dari suatu kualitas yang disimbolkan berdasarkan faktor internal maupun eksternal yang mempengaruhinya. Jika dihubungkan dengan objek penelitian yaitu Universitas Islam Kalimantan Muhammad Arsyad Al Banjari, faktor internal logo dapat dirancang berdasarkan visi dan misi perguruan tinggi, sedangkan faktor eksternal logo disusun dari keunggulan-keunggulan serta citra perguruan tinggi. Adapun faktor eksternal tersebut yang dapat mempengaruhi rancangan logo yaitu: (1) program studi unggulan, (2) akreditasi perguruan tinggi, (3) lulusan yang dapat bersaing di dunia kerja, (4) kualitas jasa yang ditawarkan oleh perguruan tinggi, (5) berbasis TI dan entrepreneur, (6) beasiswa, (7) prestasi yang diperoleh mahasiswa baik akademik maupun non-akademik, dan (8) career center dan alumni.

Faktor-faktor inilah yang mampu memberikan nilai lebih, kekhasan, dan keunikan pada sebuah logo perguruan tinggi sehingga mampu melekat dengan kuat dalam pikiran dan hati masyarakat. Sebuah logo yang baik dan berhasil akan menimbulkan sugesti yang kuat bagi masyarakat, membangun kepercayaan, dan menimbulkan rasa bangga dan memiliki bagi mahasiswa maupun dosen perguruan tinggi tersebut. Logo bahkan mampun menjalin kesatuan dan solidaritas diantara keluarga besar perguruan tinggi yang akhirnya dapat berpengaruh dengan meningkatnya motivasi belajar mengajar dan prestasi demi kemajuan perguruan tinggi.

Logo menurut Supriyono [4] merupakan bagian dari marketing tools yang sangat menentukan kesuksesan sebuah produk atau jasa, karena logo adalah hal yang pertama kali dilihat oleh audiens. Dari penjelasan tersebut logo sangat penting sebagai identitas visual yang mampu memberikan citra positif, identifikasi, serta bonafiditas dari perguruan tinggi yang pada akhirnya merupakan refleksi dari citra yang ditampilkan ke publik.

\section{HASIL DAN PEMBAHASAN}

Proses perancangan logo dilakukan melalui beberapa tahapan yaitu: (1) mempelajari design brief, (2) mengadakan riset dan brainstorming ide, (3) membuat alternatif 
desain logo, (4) presentasi kepada stakeholder, (5) revisi dan penyempurnaan desain logo.

Pada tahap pertama, peneliti mempelajari design brief yaitu mempelajari konsep perancangan berupa visi dan misi serta keunggulan-keunggulan perguruan tinggi yang didapat dari dokumentasi, wawancara dengan stakeholder terkait, serta mengumpulkan informasi pada website resmi Universitas Islam Kalimantan Muhammad Arsyad Al Banjari. Adapun visi Universitas Islam Kalimantan Muhammad Arsyad Al Banjari adalah menjadi universitas yang unggul dalam kecerdasan intelektual, emosional dan spiritual yang menekankan pada pengembangan ilmu pengetahuan, teknologi, seni dan ilmu keislaman, serta pelestarian dan pengkayaan budaya bangsa yang Islami. Sedangkan misi Universitas Islam Kalimantan Muhammad Arsyad Al Banjari adalah (1) menyelenggarakan tri dharma perguruan tinggi dengan prinsip belajar sepanjang hayat yang dilandasi dengan pembinaan nilai-nilai hidup islami, (2) mengembangkan kebebasan berpikir ilmiah yang dijiwai oleh keislaman dan semangat ketauhidan, (3) mengembangkan jiwa kewirausahaan dalam berbagai bidang ilmu pengetahuan, teknologi, seni dan ilmu keislaman.

Setelah mempelajari design brief, maka tahap selanjutnya adalah mengadakan riset dan brainstorming ide. Riset yang dimaksud adalah membandingkan logo-logo perguruan tinggi, setelah itu mencari beberapa alternatif ide logo di internet sebagai sumber inspirasi. Riset dan brainstorming ide tersebut kemudian dituangkan dengan membuat beberapa sketsa kasar (rough layout).

Pada tahap ketiga, peneliti kemudian membuat alternatif desain logo dari sketsasketsa kasar tahap kedua. Dari beberapa sketsa kasar tersebut kemudian dipilih beberapa alternatif untuk dikembangkan dan disempurnakan ditahap selanjutnya.
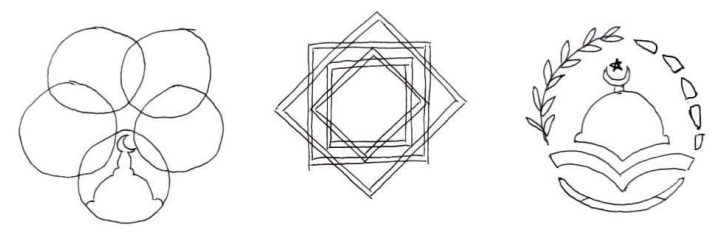

Gambar 3 Alternatif desain logo

Tahap keempat yaitu presentasi kepada stakeholder. Dalam presentasi tersebut peneliti menunjukkan alternatif desain logo kepada stakeholder dan mencatat pendapat dan masukan dari mereka untuk penyempurnaan logo.

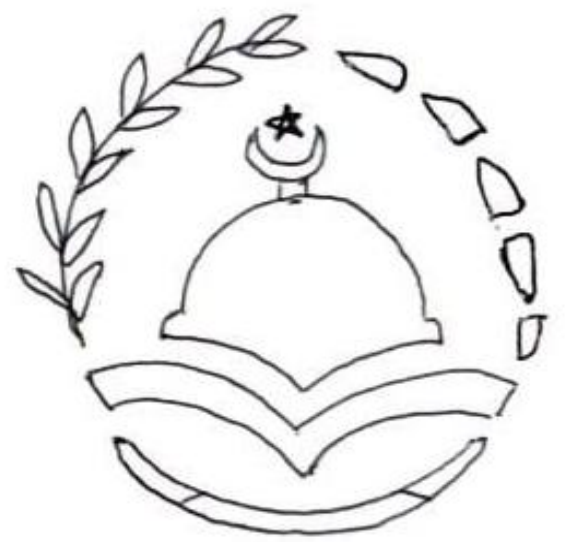

Gambar 4 Rancangan logo yang dipilih untuk disempurnakan

Tahap kelima yaitu revisi dan penyempurnaan desain logo. Ini adalah tahap terakhir dari perancangan logo dengan menyempurnakan logo dari hasil masukan stakeholder. Logo didesain dengan menggunakan software Adobe Illustrator.

Pada rancangan logo terdapat gambar padi, kapas, kubah masjid, bulan bintang, intan, buku, jukung (perahu), dan air yang merupakan perwakilan dan versi minimalis dari lambang Universitas Islam Kalimantan Muhammad Arsyad Al Banjari. Warna rancangan logo didominasi warna hijau, kuning, cokelat, dan biru. Sedangkan pada teks peneliti menggunakan font Raleway. 


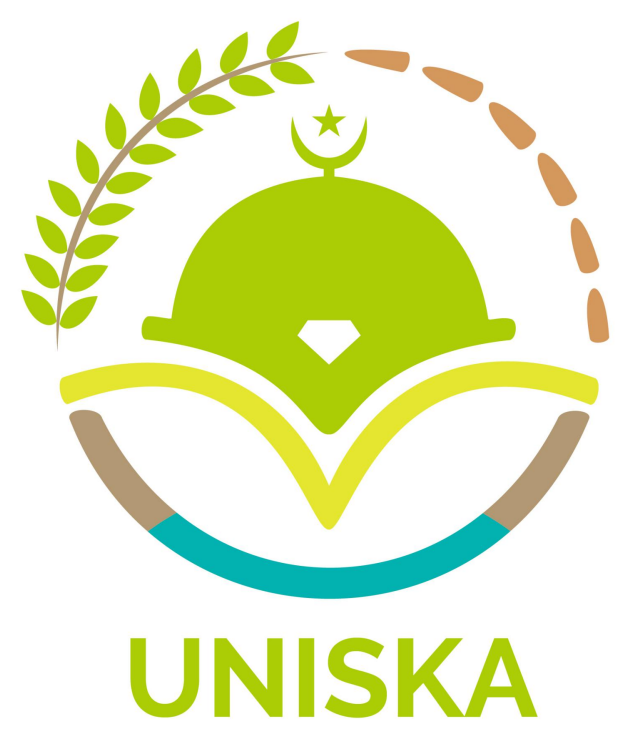

Gambar 5 Rancangan logo final Universitas Islam Kalimantan Muhammad Arsyad Al Banjari

\section{KESIMPULAN}

Logo mempunyai peran yang penting dalam membentuk identitas visual khususnya dalam branding perguruan tinggi. Perancangan identitas visual ini dapat digunakan sebagai metode dan proses perancangan logo dengan menghadirkan urutan dari tahap awal hingga akhir penciptaan sebuah karya desain.

\section{REFERENSI}

[1] Rustan, S. (2010). Layout Dasar \& Penerapannya. Jakarta: PT Gramedia Pustaka Utama.

[2] Lamb, C. W., Hair, J. F., McDaniel, C. (2001). Pemasaran. Jakarta: Salemba.

[3] Sugiyono. (2015). Metode Penelitian \& Pengembangan Research and Development. Bandung: Alfabeta.

[4] Supriyono, R. (2017). Desain Komunikasi Visual Teori dan Aplikasi. Yogyakarta: Andi. 